\title{
Boiler parametric study to decrease irreversibility
}

\author{
Mehdi bakhshesh ${ }^{1}$ and Amir Vosough ${ }^{2^{*}}$ \\ ${ }^{1}$ Department of Mechanics, Behbahan Branch, Islamic Azad University, Behbahan, Iran \\ ${ }^{2}$ Department of Mechanics, Mahshahr Branch, Islamic Azad University, Mahshahr, Iran \\ *Vosoogh_amir@yahoo.com
}

\begin{abstract}
In this paper, the useful concept of energy and exergy utilization is analyzed, and applied to the boiler system. Energy and exergy flows in a boiler have been shown in this paper. The energy and exergy efficiencies have been determined as well. In a boiler, the energy and exergy efficiencies are found to be $89.21 \%$ and $45.48 \%$, respectively. A boiler energy and exergy efficiencies are compared with others work as well. It has been found that the combustion chamber is the major contributor for exergy destruction followed by heat exchanger of a boiler system. Furthermore, Modifications are examined to increase gas-fired steam power plant efficiency by reducing irreversibilities in the steam generator, including Decreasing the fraction of excess combustion air, and/or the stack-gas temperature. Overall-plant energy and exergy efficiencies both increase by $0.19 \%, 0.37 \%$ respectively when the fraction of excess combustion air decreases from 0.4 to 0.15 , and by $0.84 \%, 2.3 \%$ when the stack-gas temperature decreases from $137^{\circ} \mathrm{C}$ to $90^{\circ} \mathrm{C}$
\end{abstract}

Keywords. Exergy efficiency, energy efficiency, super critical thermal power plant, excess air, stack gas temperature

\section{Introduction}

The general energy supply and environmental situation requires an improved utilization of energy sources. Therefore, the complexity of power-generating units has increased considerably. Plant owners are increasingly demanding a strictly guaranteed performance. This requires thermodynamic calculations of high accuracy. As a result, the expenditure for thermodynamic calculation during design and optimization has grown tremendously (Dincer \& AlMuslim, 2001). The most commonly-used method for evaluating the efficiency of an energy-conversion process is the first-law analysis. However, there is increasing interest in the combined utilization of the first and second laws of thermodynamics, using such concepts as exergy (availability, available energy), entropy generation and irreversibility (exergy destruction) in order to evaluate the efficiency with which the available energy is consumed. Exegetic analysis allows thermodynamic evaluation of energy conservation, because it provides the tool for a clear distinction between energy losses to the environment and internal irreversibilities in the process.

A thermal power plant is a good example of the utilization of exergy analysis. According to energy (firstlaw) analysis, energy losses associated with the condenser are carried into the environment by the cooling water and are significant because they represent about half of the energy input to the plant. An exergy (secondlaw) analysis, however, shows that virtually none of the exergy (resource which went into the power plant) is lost in that water. The real loss is primarily back in the boiler where entropy was produced. Thus, it is not reasonable to attempt to take advantage of the energy lost in the condenser (Gallow \& Milanez, 1990). Recently, exergy analysis has become a key aspect in providing a better understanding of the process, to quantify sources of inefficiency, to distinguish quality of energy (or heat) used (Gallow \& Milanez, 1990; Habib \& Zubair, 1992; Dincer \& Al-Muslim, 2001; Cihan et al., 2006). Exergy is defined as the maximum theoretical useful work (or maximum reversible work) obtained as a system interacts with an equilibrium state. Exergy is generally not conserved as energy but destructed in the system. Exergy destruction is the measure of irreversibility that is the source of performance loss. Therefore, an exergy analysis assessing the magnitude of exergy destruction identifies the location, the magnitude and the source of thermodynamic inefficiencies in a thermal system (Song et al., 2002).

Boiler efficiency therefore has a great influence on heating- related energy savings. Thus, it is important to maximize the heat transfer to the water and minimize the heat losses in the boiler. Heat can be lost from boilers by a variety of methods, including hot flue gas losses, radiation losses and, in the case of steam boilers, blow-

\section{Fig. 1. Schematic diagram of preheater air and supercritical boiler}

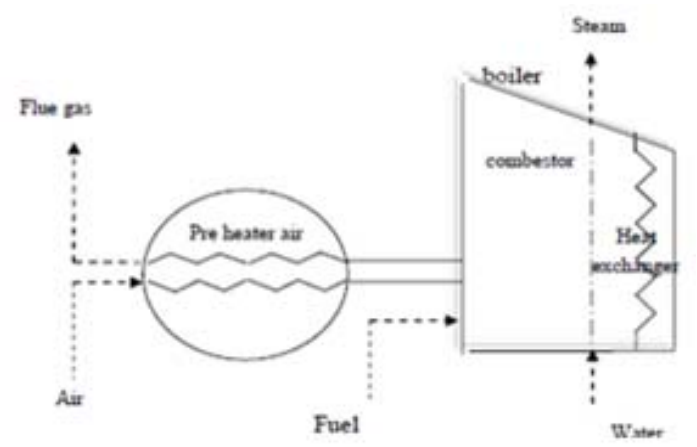

Research article

CCIndian Society for Education and Environment (iSee)
"Boiler parametric study" http://www.indjst.org
Mehdi bakhshesh \& Amir Vosough Indian J.Sci.Technol. 
down losses (ERC ,2004) etc. To optimize the operation of a boiler plant, it is necessary to identify where energy wastage is likely to occur. A significant amount of energy is lost through flue gases as all the heat produced by the burning fuel cannot be transferred to water or steam in the boiler. As the temperature of the flue gas leaving a boiler typically ranges from 150 to 250 1C, about10$30 \%$ oftheheatenergyislostthroughit.

A typical heat balance in a boiler is shown in Fig. 1 . Since most of the heat losses from the boiler appear as heat in the flue gas, the recovery of this heat can result in substantial energy saving (Jayamaha \& Lalln, 2008). This indicates that there are huge savings potentials of a boiler energy savings by minimizing its losses. Having been around for centuries, the technology involved in a boiler can be seen as having reached a plateau, with even marginal increase in efficiency painstakingly hard to achieve (Sonia et al., 2008). This work aims to identify and assess methods for increasing efficiencies of steam power plants, to provide options for improving their economic and environmental performance. In this study, several measures to improve efficiency, primarily based on exergy analysis, are considered. The modifications considered here, which increase efficiency by reducing the irreversibility rate in the steam generator, are decreasing the fraction of excess combustion air and/or decreasing the stack-gas temperature. The impact of implementing these measures on efficiencies and losses is investigated.

\section{Exergy analysis}

The process flow diagram for the boiler and power plant is shown in Fig. 1 and 2. The process parameters for the power plant and boiler are shown in Table 1 and 2 . The following thermodynamic analysis of the power plant will consider the balances of mass, energy, entropy and exergy. Unless otherwise specified, the changes in kinetic and potential energies will be neglected and steady state flow will be assumed. For a steady state process, the mass balance for a control volume system in Figure. 1 can be written as

$$
\sum_{i} \dot{m}_{l}=\sum_{i} \dot{m}_{e}
$$

The energy balance for a control volume system is written as

$$
\sum_{i} \dot{E}_{l}+\dot{Q}=\sum_{\text {out }} E_{\text {out }}+\dot{W}
$$

The entropy balance for a control volume system is

$$
\sum_{i} \dot{S}+\sum_{i} \frac{\dot{Q}}{T}+S_{\text {gen }}=\sum_{\text {out }} S+\sum_{\text {out }} \frac{\dot{Q}}{T}
$$

The exergy balance for a control volume system is written as

$$
\begin{aligned}
& \sum_{i} E_{x, l}^{\cdot}+\sum_{k}\left(1-\frac{T}{T_{k}}\right) \dot{Q_{k}}+\dot{Q} \\
& =\sum_{\text {out }} E_{x, \text { out }}+W^{\prime}+E_{x, d}^{\cdot}
\end{aligned}
$$

Where the exergy rate of a stream is

$$
E_{x, i}=\dot{m} e_{x}
$$

$$
\dot{m} e_{x}=\dot{m}\left(e_{x}^{t m}+e_{x}^{c h}\right)
$$

\section{Fig. 2. Schematic diagram of Ramin supercritical power plant cycle}

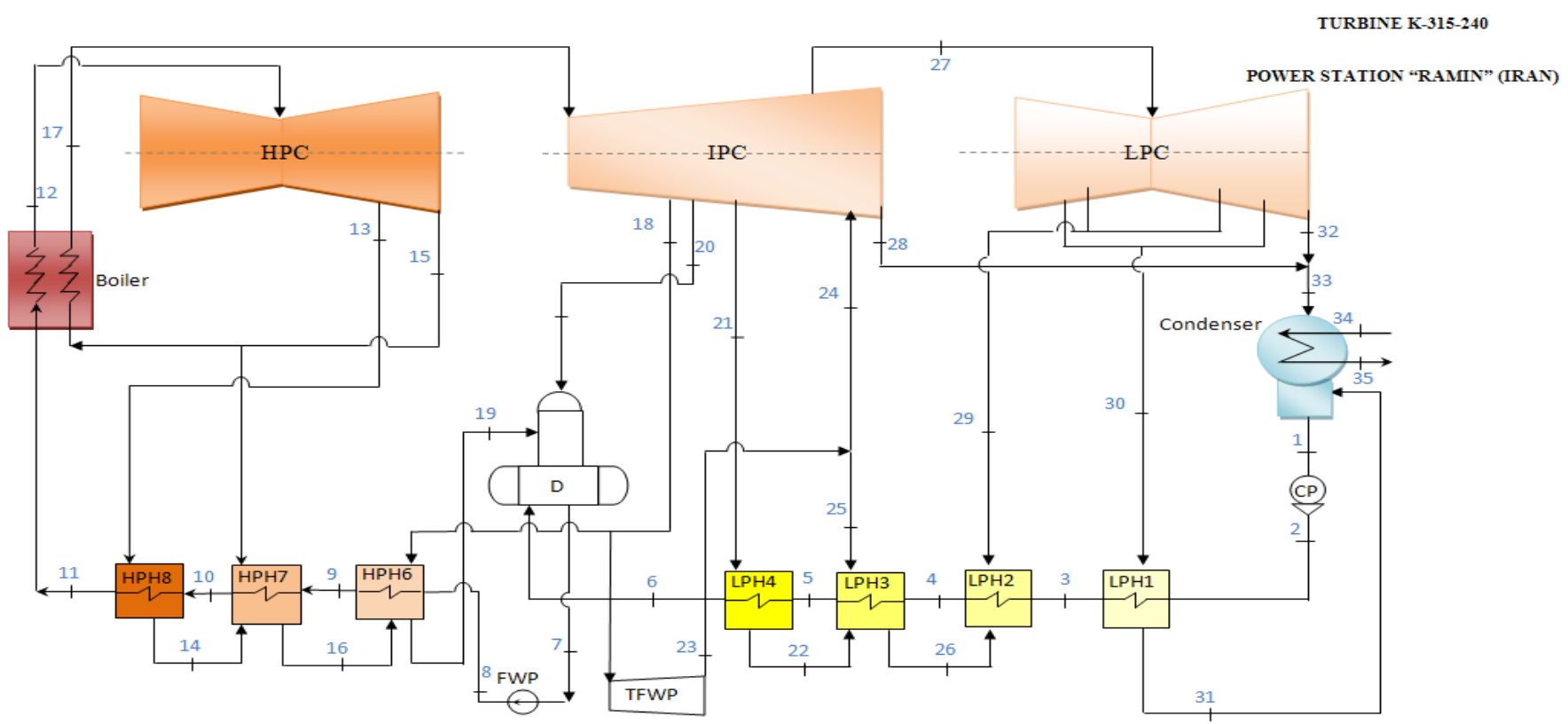


Indian Journal of Science and Technology

Vol. 5 No. 4 (Apr 2012)

ISSN: 0974- 6846

Table 1Thermodynamic properties of power plant at different nodes $\left(T_{a}=25^{\circ} \mathrm{C}\right)$

\begin{tabular}{|c|c|c|c|c|c|c|}
\hline Node & $\mathrm{P}(\mathrm{M} \mathrm{Pa})$ & $\mathrm{T}\left({ }^{\circ} \mathrm{C}\right)$ & $\mathrm{h}(\mathrm{kJ} / \mathrm{kg})$ & $\mathrm{s}(\mathrm{kJ} / \mathrm{kg} \cdot \mathrm{K})$ & $\dot{\mathrm{M}}(\mathrm{kg} / \mathrm{s})$ & $e_{x}(k J / k g)$ \\
\hline 1 & 0.066 & 49 & 205.2 & 0.691 & 186.0 & 3.93 \\
\hline 2 & 2.290 & 51 & 215.5 & 0.716 & 186.0 & 7.39 \\
\hline 3 & 2.080 & 67 & 244.5 & 0.805 & 186.0 & 9.17 \\
\hline 4 & 1.870 & 91 & 382.5 & 1.210 & 218.1 & 27.18 \\
\hline 5 & 1.660 & 120 & 504.8 & 1.526 & 216.1 & 54.31 \\
\hline 6 & 1.450 & 149 & 628.6 & 1.831 & 218.1 & 87.54 \\
\hline 7 & 0.700 & 164 & 693.1 & 1.983 & 282.6 & 106.70 \\
\hline 8 & 33.130 & 172 & 730.1 & 2.062 & 282.6 & 120.89 \\
\hline 9 & 32.800 & 201 & 857.9 & 2.340 & 282.6 & 165.80 \\
\hline 10 & 32.470 & 252 & 1095.0 & 2.811 & 282.6 & 262.5 \\
\hline 11 & 31.220 & 282 & 1243.0 & 3.085 & 282.6 & 328.98 \\
\hline 12 & 24.000 & 540 & 3316.0 & 6.169 & 282.6 & 1482.00 \\
\hline 13 & 6.918 & 360 & 3047.5 & 6.283 & 20.1 & 1180.00 \\
\hline 14 & 6.640 & 261 & 1139.0 & 2.893 & 20.1 & 282.15 \\
\hline 15 & 4.480 & 303 & 2952.0 & 6.300 & 255.8 & 1080.00 \\
\hline 16 & 4.280 & 208 & 889.4 & 2.402 & 50.0 & 178.20 \\
\hline 17 & 4.080 & 540 & 3536.0 & 7.196 & 228.5 & 1396.00 \\
\hline 18 & 1.710 & 414 & 3282.0 & 7.249 & 44.9 & 1127.00 \\
\hline 19 & 1.620 & 180 & 763.6 & 2.139 & 62.4 & 130.70 \\
\hline 20 & 1.110 & 355 & 3166.0 & 7.267 & 1.5 & 1005.00 \\
\hline 21 & 0.532 & 264 & 2988.0 & 7.295 & 11.5 & 818.90 \\
\hline 22 & 0.500 & 151 & 637.0 & 1.853 & 11.5 & 89.38 \\
\hline 23 & 0.238 & 217 & 2901.0 & 7.494 & 33.0 & 673.05 \\
\hline 24 & 0.228 & 236 & 2941.0 & 7.591 & 20.1 & 683.60 \\
\hline 25 & 0.222 & 216 & 2901.0 & 7.523 & 9.2 & 663.90 \\
\hline 26 & 0.222 & 102 & 427.6 & 1.329 & 20.7 & 35.95 \\
\hline 27 & 0.223 & 181 & 2830.0 & 7.371 & 126.9 & 638.40 \\
\hline 28 & 0.011 & 47 & 2442.2 & 7.666 & 62.9 & 162.99 \\
\hline 29 & 0.0938 & 108 & 2693.0 & 7.435 & 11.2 & 482.6 \\
\hline 30 & 0.0229 & 63 & 2501.0 & 7.525 & 6.6 & 263.10 \\
\hline 31 & 0.0873 & 61 & 255.4 & 0.844 & 6.6 & 8.47 \\
\hline 32 & 0.0105 & 46 & 2440 & 7.674 & 114.2 & 159.01 \\
\hline 33 & 0.0107 & 46 & 2441 & 7.682 & 171.6 & 158.03 \\
\hline 34 & 0.25 & 27 & 113.3 & 0.395 & 2778.0 & 0.27 \\
\hline 35 & 0.25 & 37 & 146.6 & 0.505 & 2778.0 & 1.25 \\
\hline
\end{tabular}


The above exergy balance is written in a general form. For the combustion process, the heat input will be included when calculating the chemical exergy of gas. The heat exergy term in Eq. (4) will be used to calculate the exergy loss associated with heat loss to the surroundings. The specific exergy is given by:

$$
e_{x}^{t m}=\left(h-h_{0}\right)-T_{0}\left(S-S_{0}\right)
$$

\section{Modeling and simulation of boiler}

Fuel of boiler is natural gas including $\mathrm{CH}_{4}, \mathrm{C}_{2} \mathrm{H}_{6}$,

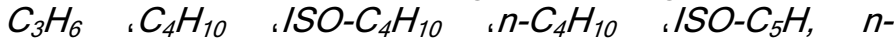
$\mathrm{C}_{5} \mathrm{H}_{12} \mathrm{CO} \mathrm{CO}_{2}, \mathrm{~N}_{2}$. The energy and exergy analysis of the cycle has been made using the 'EES' software. The combustion process is assumed to be complete as follows:

$$
\begin{aligned}
& \sum_{i=1}^{l}\left[f_{i} C_{n_{i}} H_{m_{i}}+\alpha f_{i}\left(n_{i}+\frac{m_{i}}{4}\right) O_{2}+3.76 \alpha f_{i}\left(n_{i}+\frac{m_{i}}{4}\right) N_{2}\right] \\
& +c \mathrm{CO}_{2}+d N_{2}+n_{v, a}+H_{2} O \rightarrow \sum\left(f_{i} n_{i}+c\right) C O_{2} \\
& +\sum\left(\frac{m_{i} f_{i}}{2}+n_{v, a}\right) H_{2} O+(\alpha-1)\left[\sum f_{i}\left(n_{i}+\frac{m_{i}}{4}\right)\right] o_{2} \\
& +\left[\sum 3.76 \alpha f_{i}\left(n_{i}+\frac{m_{i}}{4}\right)+d\right] N_{2}
\end{aligned}
$$

Where $\alpha$ is the percentage of the excess air, $f_{i}$ is the molar fraction of the fuel components parts and $n_{v, a}$ is the number of moles of the humidity entering the combustion chamber with dry air. The unknown coefficients can be calculated by a molar balance and then the energy and exergy balance of the combustion gases can be performed. For different components of the cycle, the exergy destruction and the exergy efficiency can be obtained by applying exergy balance as follows:

$$
\begin{aligned}
\dot{E}_{x, b}^{d}= & \dot{m}_{f} e_{x, f}^{c h}+\dot{W}_{i n, b}+\dot{m}_{a} e_{x, a}-\dot{m}_{g} e_{x, g} \\
& +\sum_{i n} \dot{m}_{w} e_{x, w}-\sum_{o u t} \dot{m}_{w} e_{x, w} \\
\eta_{I I, b}= & \frac{\sum_{o u t, b} \dot{m}_{w} e_{x, w}-\sum_{i n, b} \dot{m}_{w} e_{x, w}}{\dot{m}_{f} e_{x, f}^{c h}+\dot{m}_{a} e_{x, a}+\dot{w}_{i n, b}} \\
\eta_{I, b}= & \frac{\sum_{o u t, b} \dot{m}_{w} h_{w}-\sum_{i n, b} \dot{m}_{w} h_{w}}{\dot{m}_{f} L H V+\dot{m}_{a} h_{a}+\dot{w}_{i n, b}}
\end{aligned}
$$

The energy balance equation for calculating adiabatic flame temperature is:

$$
\sum N_{r}\left(\bar{h}_{f}^{0}+\bar{h}-\bar{h}^{0}\right)_{r}=\sum N_{p}\left(\bar{h}_{f}^{0}+\bar{h}-\bar{h}^{0}\right)_{p}
$$

The destroyed exergy due to combustion process and heat transfer can be expressed as:

$$
\dot{E}_{x, d, c}=\dot{m}_{f} e_{x, f}^{c h}+\dot{m}_{a} e_{x, a}-\dot{m}_{p} e_{x, p, \text { adiabatic }}
$$

$\dot{E}_{x, d, h t}=\dot{E}_{x, d, b}-\dot{E}_{x, d, c}(14)$

The second law efficiency of combustion process, heat transfer process of boiler and power plant can be expressed as:

$$
\begin{aligned}
& \eta_{I I, c}=\frac{\dot{m}_{p} e_{x, p, \text { adiabatic }}}{\dot{m}_{f} e_{x, f}^{c h}+\dot{m}_{a} e_{x, a}} \\
& \eta_{I I, h t}=\frac{\sum_{\text {out }} m_{w} e_{x, w}-\sum_{i n} m_{w} e_{x, w}}{\dot{m}_{p} e_{x, p, \text { adiabatic }}-\dot{m}_{p} e_{x, p, \text { out }, \text { adiabatic }}} \\
& \eta_{I I, p p}=1-\frac{\dot{E}_{x, d, p p}}{\dot{m}_{f} e_{x, f}^{c h}}
\end{aligned}
$$

\section{Results and discussion}

Fig. 3 shows that the boiler has the most exergy losses in power plant and Fig. 4 shows that the condenser

Fig.3. Present ratio irreversibility in power plant component

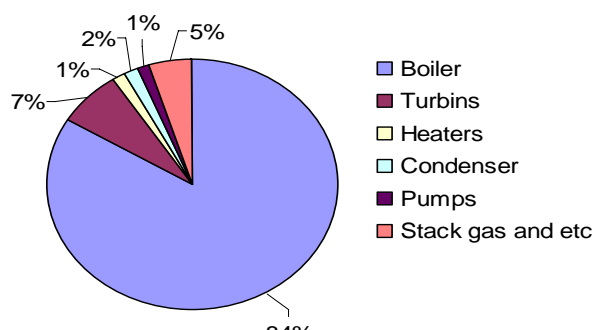

$84 \%$

Fig. 4. Present ratio of heat balance in power plant component

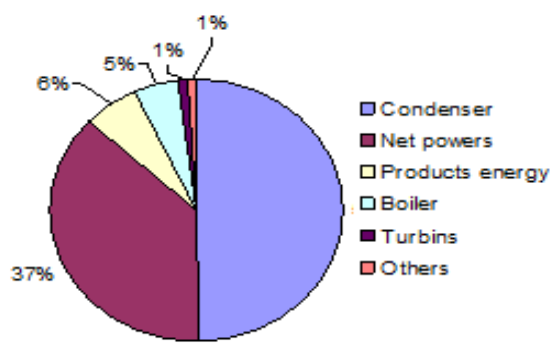

Fig. 5. Combustion gas product temperature vs

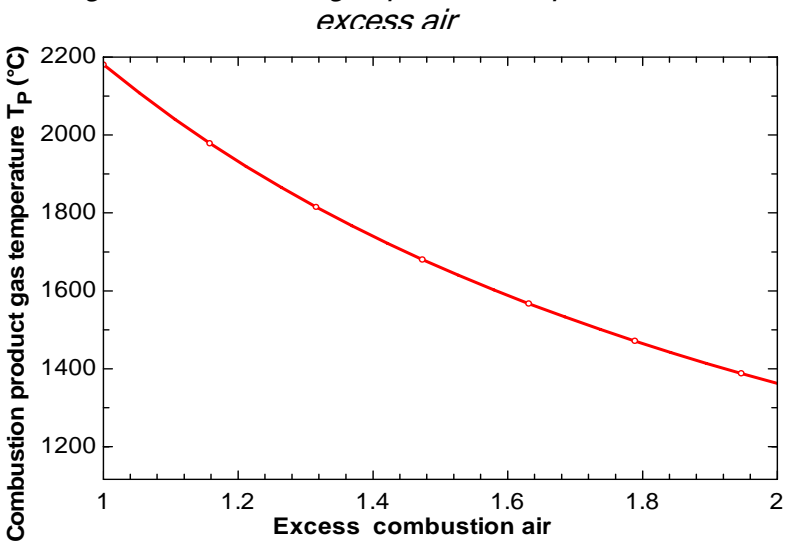

Fig. 6. Irreversibility rate of combustion and heat exchanger process vs excess air

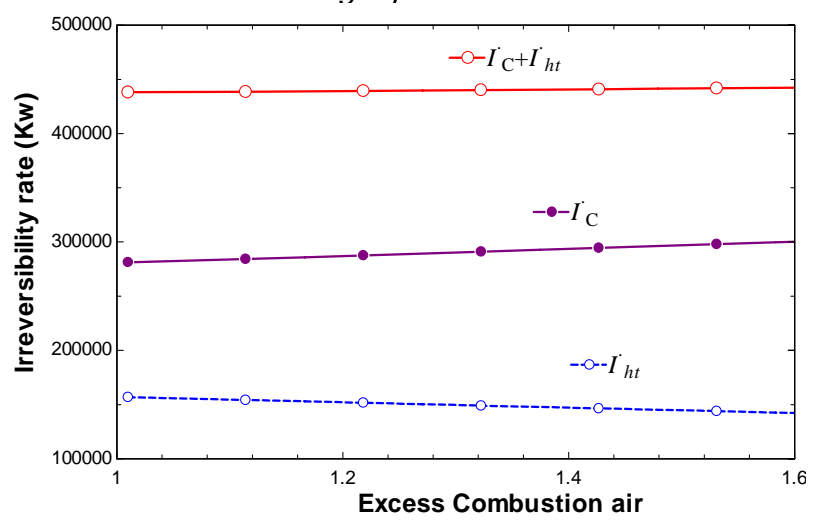

Mehdi bakhshesh \& Amir Vosough Indian J.Sci.Technol. 
Fig. 7. Exergy efficiency of boiler and power plant vs excess air

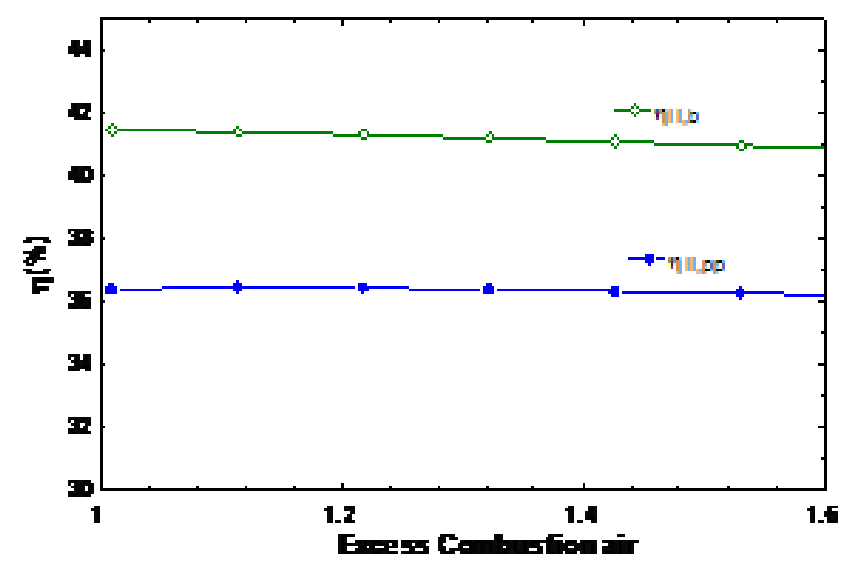

Fig. 8. Irreversibility rate of combustion and heat exchanger process vs stack gas temperature

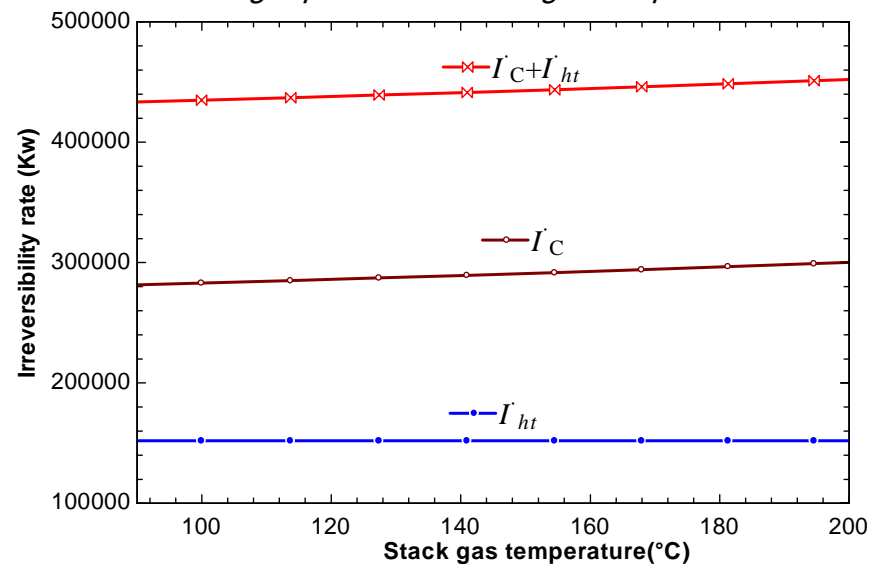

Fig.9. Exergy efficiency of boiler and power plant vs stack gas temperature

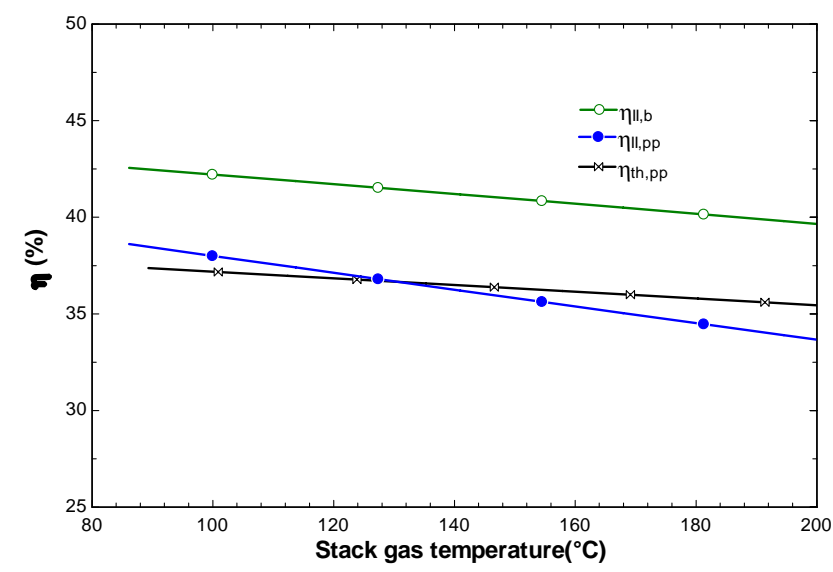

Vol. 5 No. 4 (Apr 2012)

ISSN: 0974- 6846

has the most energy losses in power plant. These figures illustrate the difference between energy and exergy analyses.

Table 2. Operating values of the power plant

\begin{tabular}{|l|l|l|}
\hline Gas mass flow rate & 16.76 & $\mathrm{~kg} / \mathrm{s}$ \\
\hline Gas lower heat value & 48500 & $\mathrm{~kJ} / \mathrm{kg}$ \\
\hline Air mass flow rate & 320.7 & $\mathrm{~kg} / \mathrm{s}$ \\
\hline Maximum gas temperature in boiler & 2000 & ${ }^{\circ} \mathrm{C}$ \\
\hline Gas exit temperature from boiler & 137 & ${ }^{\circ} \mathrm{C}$ \\
\hline Feed water mass flow rate & 1017.5 & $\mathrm{ton} / \mathrm{hr}$ \\
\hline Feed water pressure & 24 & $\mathrm{MPa}$ \\
\hline Feed water inlet temperature & 282.5 & $\mathrm{~kg} / \mathrm{s}$ \\
\hline Steam temperature & 540 & ${ }^{\circ} \mathrm{C}$ \\
\hline Extraction steam pressure & 4.48 & $\mathrm{MPa}$ \\
\hline Extraction steam temperature & 303 & ${ }^{\circ} \mathrm{C}$ \\
\hline Extraction steam mass flow & 255.8 & $\mathrm{~kg} / \mathrm{s}$ \\
\hline Reheated steam temperature & 540 & ${ }^{\circ} \mathrm{C}$ \\
\hline Cooling water mass flow rate & 10000 & $\mathrm{~kg} / \mathrm{s}$ \\
\hline
\end{tabular}

Table 3 shows the result of exergy analyses for the process of boiler. It has been found that the combustion process is the major contributor for exergy destruction followed by heat exchanger of a boiler system.

Fig. 5 and 6 shows the variations of adiabatic flame temperature, irreversibility rate of combustion and heat exchanger process in boiler with excess combustion air Fig.7 illustrate boiler and plant exergy efficiency with excess combustion air. The following main points are observed from Fig.5, 6, 7. First, it is seen in Fig.6 that, as the fraction of excess combustion air decreases, the steam-generator irreversibility rate decreases slightly, while within that device the irreversibility rate associated with combustion decreases and that associated with heat transfer increases. The term $\dot{I}_{c}$ decreases because the temperature of the product gas $T p$ increases with decreasing excess combustion air, as seen in Fig. 2, so that the exergy of the product gas increases. However, the irreversibility rate $\dot{I}_{h t}$ increase, because a higher combustion-gas temperature $T p$ increases the temperature difference between that gas and the $\mathrm{H}_{2} \mathrm{O}$ flows. The total irreversibility rate of the steam generator $\dot{I}_{c}+\dot{I}_{h t}$ nevertheless decreases with decreasing excess combustion air, due to the decreased fuel consumption for the combustion process as decreases. Second, the overall plant exergy efficiency is seen in Fig. 4 to increase with decreasing with excess air, with and mainly due to the increasing steam-generator exergy efficiency.

The overall plant exergy efficiencies increase by nearly $2.3 \%$ when the value of excess combustion air is reduced from 0.40 to 0.15 . A significant amount of heat

Table 3. The result of exergy analyses for the boiler process

\begin{tabular}{|l|l|l|l|l|}
\hline \multicolumn{2}{|c|}{} & Destroyed exergy & Destroyed exergy to total exergy destroyed & Second law efficiency (\%) \\
\hline \multirow{2}{*}{$\begin{array}{l}\text { Boil } \\
\text { er }\end{array}$} & $\begin{array}{l}\text { Combustion } \\
\text { process }\end{array}$ & 253.37 & 34.23 & 69.94 \\
\cline { 2 - 6 } & $\begin{array}{l}\text { Heat transfer } \\
\text { process }\end{array}$ & 187.63 & 45.53 & 69.42 \\
\cline { 2 - 6 } & Total & 441.00 & 80.45 & 41.12 \\
\hline
\end{tabular}


energy is lost through flue gases as all the heat produced by burning fuel cannot be transferred to water or steam in the boiler. As the temperature of the flue gas leaving a boiler is in the range of $150-250^{\circ} \mathrm{C}$, about $10-30$ percent of the heat energy is lost through it. Therefore, recovering part of the heat from the flue gas can help to improve the efficiency ofthe boiler and power plant. Heat can be recovered from the flue gas by passing it through a heat exchanger. The recovered heat can be used to pre-heat boiler feed water, combustion air and this will absolutely save the energy use. The flue gas is usually at high temperature to ensure that it is enough to pre-heat the fluid. Figure 8 shows the effect of stack gas temperature on the irreversibility rate of combustion and heat exchange process in boiler. As shown in Fig.8 the irreversibility of heat exchange process in boiler increase because the difference temperature between combustion products and working fluid increased but the irreversibility rate of combustion reduces due to having better combustion process. The irreversibility rate of boiler totally increases with the increasing in stack gas temperature. In Fig.9 exergy efficiency of boiler vs stack gas temperature has been shown, exergy efficiency reduced $1.7 \%$ when stack gas temperature increase from $87^{\circ} \mathrm{C}$ to $130^{\circ} \mathrm{C}$.

Table 4. changes in the boiler and power plant performance by changing simultaneously in stack gas temperature and excess air

\begin{tabular}{|c|l|l|l|l|}
\hline Excess air & \multicolumn{2}{|c|}{1.1} & \multicolumn{2}{c|}{1.4} \\
\hline $\begin{array}{c}\text { Stack gas temperature } \\
\left({ }^{\circ} \mathrm{C}\right)\end{array}$ & 90 & 137 & 90 & 137 \\
\hline$\eta_{I I, p p}(\%)$ & 39.5 & 37.37 & 39.3 & 37.00 \\
\hline$\eta_{t h, p p}(\%)$ & 37.82 & 36.89 & 37.62 & 36.78 \\
\hline$\eta_{I I, b}(\%)$ & 42.44 & 41.43 & 42.16 & 41.12 \\
\hline$\dot{I}_{b}(\mathrm{Kw})$ & 431969 & 445788 & 441650 & 458872 \\
\hline
\end{tabular}

Increasing power plant efficiency by changing excess air and stack gas temperature simultaneously

The power plant performance can be increased by reducing the stack gas temperature or reducing of excess air (Fig.7 and 9). Further increase in plant performance occurred by reducing the excess air and stack gas temperature simultaneously. Table 4 shows the changes in the boiler and power plant performance by changing simultaneously in stack gas temperature and excess air. As the excess air and exhaust gas temperature lowered, the boiler and plant efficiency has improved.

Conclusion

The present investigation of the changes in steamgenerator irreversibility rate and plant efficiency, from decreasing the fraction of excess combustion air and/or decreasing the stack-gas temperature, leads to many useful findings. The results show that decreasing either the fraction of excess combustion air or the stack-gas temperature causes the irreversibility rate in steam generator to decrease, mainly due to the decrease in the irreversibility rate associated with combustion in that device. The improvement in plant exergy efficiencies is $0.37 \%$ when the fraction of excess air decreases from 0.4 to 0.15 and $2.3 \%$ when the stack-gas temperature decreases from $137{ }^{\circ} \mathrm{C}$ to $90{ }^{\circ} \mathrm{C}$. The improvement becomes lesser when these measures are applied simultaneously but becomes higher when applied separately. It would seem to be worthwhile to consider the modifications described in this paper, in both plant retrofits and new designs. The results are likely to be useful to designers of electrical generating stations and can be combined with economic assessments such as the one reported for a coal-fired steam power plant.

Acknowledgements

Financial support for this research was provided by the Behbahan Branch, Islamic Azad University,Behbahan, Iran with title: Boiler parametric study to decrease irreversibility

Reference

1. Cihan A, Hacıhafızog luO and Kahveci K (2006) Energy-exergy analysis and modernization suggestions for a combined-cycle power plant. Int. J. Energy Res. 30, 115-126.

2. Dincer $I$ and Al-Muslim H (2001) Thermodynamic analysis of reheat cycle steam power plants. Int.J. Energy Res. 25, 727-739.

3. ERC (2004) In: How to save energy and money in boilers and furnace systems. Energy Res. Centre (ERC), University of Cape Town, South Africa.

4. Gallow LR and Milanez LF (1990) Choice of a reference state for exergetic analysis. Energy. 15, 113-121.

5. Habib MA and Zubair SM (1992) Second-law-based thermodynamic analysis of regenerative-reheat Rankine cycle power plants. Energy. 17, 295-301.

6. Jayamaha and Lalln (2008) Energy efficient building systems. Hardbook. Mcgraw Hill Education, Europe.

7. Song TW, Kim JL, Kim TS and Roa T (2002) Exergybased performance analysis of the heavy-duty gas turbine in part-load operating conditions. Exergy. 2 (20), 105-112.

8. Sonia Yeh, Edward S and Rubin (2008) A centurial history of technological change and learning curves for pulverized coal-fired utility boilers. Energy. 3, 19962005.

\footnotetext{
Nomenclature : $e_{x}=$ Specific flow exergy $(\mathrm{kJ} / \mathrm{kg}) ; E=$ exergy $(\mathrm{kW}) ; h=$ Specific enthalpy $(\mathrm{kJ} / \mathrm{kg}) ; \dot{i}$ Irreversibility rate $(\mathrm{kW}) ; L H V=$ Low heat value $(\mathrm{kJ} / \mathrm{kg}) ; \dot{m}=$ Mass flow rate $(\mathrm{kg} / \mathrm{s}) ; N=$ Number of moles; $P=$ Pressure $(\mathrm{MPa}) ; \dot{Q}=\mathrm{Heat}$ rate $(\mathrm{kW}) ; R=\mathrm{Gas}$ universal constant $(\mathrm{kJ} / \mathrm{kmol} \mathrm{K}) ; S=$ Specific entropy $(\mathrm{kJ} / \mathrm{kg} \mathrm{K}) ; T=$ Temperature $\left({ }^{\circ} \mathrm{C}\right) ; T_{o=}$ Ambient temperature $\left({ }^{\circ} \mathrm{C}\right) ; \dot{w} t=\mathrm{Turbine}$ net output work (MW); $\Phi=$ Relative Humidity; $\boldsymbol{\eta}=$ = Thermal Efficiency; $\eta=$ Exergy Efficiency; Subscripts: $a=$ Air; $b=$ Boiler; $c=$ combustion; $d$ = Destroyed; $F=$ Fuel; $F w p=$ Feed Water Pump; $g$ = Product gas; $h e=$ Heater; $h t=$ Heat exchanger; ipc = Medium-Pressure Turbine; in =Inlet; $N G=$ Natural Gas; out = Outlet; $p p=$ Power Plant.
}

Research article

(C)Indian Society for Education and Environment (iSee)
"Boiler parametric study"

http://www.indjst.org
Mehdi bakhshesh \& Amir Vosough Indian J.Sci.Technol. 